\title{
Artificial reefs in the North-East Atlantic area: present situation, knowledge gaps and future perspectives
}

Bianca Reis ${ }^{1,2 *}$, Pieter van der Linden ${ }^{1,2}$, Isabel Sousa Pinto ${ }^{1,2}$, Emanuel Almada ${ }^{1,2,3}$, Maria Teresa Borges ${ }^{1,2}$, Alice E. Hall ${ }^{4}$, Rick Stafford ${ }^{4}$, Roger J.H. Herbert ${ }^{4}$, Jorge Lobo-Arteaga ${ }^{5,6}$, Maria José Gaudêncio ${ }^{5,6}$, Miriam Tuaty-Guerra ${ }^{5,6}$, Océane Ly ${ }^{7}$, Valentin Georges ${ }^{7}$, Mariane Audo ${ }^{7}$, Nassim Sebaibi ${ }^{7}$, Mohamed Boutouil $^{7}$, Elena Blanco-Fernandez ${ }^{8}$, João N. Franco ${ }^{1,2,9}$

${ }^{1}$ Departamento de Biologia, Faculdade de Ciências, Universidade do Porto, Rua do Campo Alegre s/n, 4150181 Porto, Portugal. Email: r.biancareis@gmail.com

${ }^{2}$ CIIMAR, Centro Interdisciplinar de Investigação Marinha e Ambiental, Terminal de Cruzeiros do Porto de Leixões, Av. General Norton de Matos s/n, 4450-208, Matosinhos, Portugal.

${ }^{3}$ MARE - Marine and Environmental Sciences Centre, Quinta do Lorde Marina, Sítio da Piedade, 9200-044, Madeira, Portugal

${ }^{4}$ Dept. Life and Environmental Sciences, Bournemouth University, Talbot Campus, Fern Barrow, BH12 5BB Poole, United Kingdom

${ }^{5}$ Instituto Português do Mar e da Atmosfera, I.P., Divisão de Oceanografia e Ambiente Marinho, Rua Alfredo Magalhães Ramalho 6, 1495-006, Lisboa, Portugal

${ }^{6}$ MARE - Centro de Ciências do Mar e do Ambiente, Universidade Nova de Lisboa, Campus de Caparica, 2829-516 Caparica, Portugal.

${ }^{7}$ Ecole Supérieure d'Ingénieurs des Travaux de la Construction de Caen, Research Laboratory on construction materials, Rue Pierre et Marie Curie 1, 14610 Épron, France

${ }^{8}$ Universidad de Cantabria, 39005 Santander, Spain

${ }^{9}$ MARE-Marine and Environmental Sciences Centre, ESTM, Politécnico de Leiria, 2520-620 Peniche, Portugal

*Corresponding author: Bianca Reis

e-mail: r.biancareis@gmail.com

CIIMAR, Centro Interdisciplinar de Investigação Marinha e Ambiental, Terminal de Cruzeiros do Porto de Leixões, Av. General Norton de Matos s/n, 4450-208, Matosinhos, Portugal 


\section{Abstract}

Artificial reefs have been deployed in multiple regions of the world for different purposes including habitat restoration and protection, biodiversity and fish stock enhancement, fisheries management and recreation. Artificial reefs can be a valuable tool for ecosystem protection and rehabilitation, helping mitigate the effects of anthropogenic impacts that we face today. However, knowledge on artificial reefs is unevenly distributed worldwide, with some regions having much more quality information available and published (e.g. European Mediterranean Sea area), while others, for instance the North-East Atlantic area, do not. Here, we provide a characterization of purposely built artificial reefs in North-East Atlantic area based on all available literature (i.e. research papers and reports), highlighting the needs and gaps that are vital for establishing future perspectives for artificial reef deployment and research. In the North-East Atlantic area, sixty-one purposely built artificial reefs have been deployed since 1970, mostly between the years 1990-2009, with Spain being the country with the highest number of artificial reefs. The most reported purpose for their deployment is fisheries productivity and habitat/species protection, although, most artificial reefs are multipurpose in order to maximise the benefits of a given financial investment. The majority of artificial reefs were submerged at $<50 \mathrm{~m}$, mainly between 10-20 m of depth. The most used designs were cubic blocks and complex designs made by an array of combined shapes, which mostly consist of concrete (79\%). From all the analysed data on artificial reefs, $67 \%$ of the cases reported surveys to assess biodiversity after the deployment. However, in $26 \%$ of those cases, data was not available. When data was available, only $31 \%$ of cases reported long-term biomonitoring surveys ( 3 years or more). Based upon these findings, we noticed a general lack of scientifically robust data, including records of species and abundance of both fish and invertebrates, as well as macroalgae. Preventing an adequate determination of the best balance between shape, construction material and bio-colonization. Critiques and suggestions are discussed in the light of current available data in order to perform more efficient research, evaluation and functioning of future artificial reefs.

KEYWORDS: Artificial reefs, design, building material, bio-monitoring, species diversity, European Atlantic 


\section{Introduction}

The use of artificial structures in the marine environment to improve and mimic features of natural habitats (e.g. shelter for marine species) has continued for thousands of years. The practice of submerging structures to create artificial environments may have been used since the Neolithic period by African peoples that noticed a greater abundance of fish near floating and submerged objects [1]. These structures were mostly rocks used by fishermen with the aim of attracting and catching fish $[2,3]$. These ancient practices evolved to the more modern concept of using artificial structures called artificial reefs (ARs). Since the mid-1800s ARs have been deployed in several regions of the world to increase fisheries catches, with the United States and Japan being pioneers in this field [4,5]. Nowadays, ARs are an important tool which, together with other management measures such as fishing quotas [6] and marine protected areas [6-10], can play an important role in impact mitigation, ecosystem restoration and recovery, especially where they can provide shelter or habitat for key species $[6,11]$. ARs can be deployed for different purposes, such as to preserve habitats and fishing resources by preventing illegal trawling, to attract and enhance production of specific commercial fish species or to promote leisure activities namely angling, scuba-diving and surfing [3,12-14]. Furthermore, these structures can also act as a natural laboratory to study the potential effects of environmental changes on biological communities $[6,14]$. The definition of an artificial reef has endured several modifications over time and it can encompass different meanings and interpretations. Jensen [12] defines an artificial reef as a submerged structure placed on the seabed deliberately to mimic some characteristics of a natural reef. According to Seaman [15], ARs can be defined by their physical features and purpose, being constructed specifically or acquired having being used for another purpose before, and having future influence on the abiotic, biotic and socioeconomic features of the surroundings.

For this study, the focus was the North-East (NE) Atlantic coast, which is characterised by highly wave-exposed shorelines as a result of the large fetch and swell caused by westerly winds. The region is mostly macrotidal with ranges of $4-10 \mathrm{~m}$, however these are significantly reduced along the Scandinavian coast and around amphidromic points [16]. The relatively proximity of the continental shelf to the lberian coast results in upwelling of cold nutrient-rich waters in spring and summer. Mean winter and summer sea surface 
temperatures range from $16-23^{\circ} \mathrm{C}$ in the south of the region at Gibraltar, to $5-11^{\circ} \mathrm{C}$ along the north-west Norwegian coast [16]. In biogeographical terms, the region straddles warm temperate (Lusitanian) zones to the south off the Iberian coast, cold temperate (Boreal) regions in the North Sea and southern Norway and the Arctic region in northern Norway [17]. Much of the intertidal coast consists of rocky shores with subtidal reefs, including kelp forests, extending from low tide to $15 \mathrm{~m}$ depth [17]. Fin fisheries and shellfisheries are predominant and widespread with aquaculture, water sports and other recreational pursuits in more sheltered regions and close to towns and cities. Many protected areas and others of marine conservation importance occur along the coast, including areas designated under the EU Habitats Directive. In the NE Atlantic area, AR guidelines established at the OSPAR convention (legislative instrument regulating international cooperation on environmental protection in the NE Atlantic) [18] are used. According to these guidelines [13], an Artificial Reef is defined as "[...] a submerged structure placed on the seabed deliberately, to mimic some characteristics of a natural reef. It could be partly exposed at some stages of the tide". It is understood that this definition excludes artificial islands, or structures, such as breakwaters, established for coastal defence purposes. According to literature, in Europe the use of ARs commenced in the second half of 1900s and was more pronounced in the Mediterranean Sea $[3,5,12]$. Here, these structures were deployed mostly for seagrass meadow protection, and enhancement of biodiversity in specific areas $[2,5,19]$. Along the rest of the European coast, the development and deployment of ARs have been slower $[3,12,14]$. In the Atlantic coast of the Iberian Peninsula, fish stock enhancement and fisheries management have been the main goals of AR construction, while conservation and/or restoration, research and recreation, have been the main purposes in northern European Atlantic regions $[3,12]$. However, despite their continuous utilization, ARs have not always had positive effects, either in terms of their aims or impacts on the environment. For example, in the early 1980s, used car tyres were deployed as AR structures in the marine protected area of Vallauris-Golfe, Juan Bay, France (NW Mediterranean coast). These were intended to attract and provide habitat for marine species, but instead they were proved to release toxic substances (e.g. heavy metals) into the water, which only later were detected in filter feeding organisms such as mussels [20]. This example of a negative outcome very clearly demonstrates that the success of artificial reef structures relies on appropriate planning, implementation and 
management actions $[14,21,22]$. Despite the importance of proper planning and testing prior and after AR deployment, there are still several knowledge gaps concerning the effects of their implementation. These include socioeconomic perspectives, the extent of reliable monitoring, an assessment of the relationship between climate change and biological communities of ARs and overall interdisciplinary studies [22,23]. Information regarding physical details of ARs, such as design, construction materials, and characterization of the deployment site and environmental conditions is also scarce $[3,14,24]$. Artificial Reef science is a growing area of multidisciplinary research and may contribute to other complementary fields [25]. By studying aspects of AR functioning, productivity and ecosystem features [26], the broadening of knowledge regarding other ecological aspects, such as trophic interactions, predation and mortality, can be achieved $[3,23,25]$. This, combined with other factors such as the importance of ARs for habitat restoration, proper habitat management, and socioeconomic factors, namely fisheries, contributes to the importance of producing reliable studies in this field $[15,27]$. The present study aims to provide a comprehensive characterization of the ARs present in the NE Atlantic area as a baseline from which to develop innovative ARs for sustainable management of the marine ecosystems of the Atlantic area, highlighting the needs and gaps that must be addressed and which are vital to establish future perspectives for successful ARs deployment and management. Here we extract all the critical information such as deployment characteristics, construction materials, shape, monitoring and biological data. The resulting body of information and its analysis will be useful for future deployments of ARs and for managers and researchers to establish the priorities within the scope of future AR utilization and functioning within the NE Atlantic area. 


\section{Materials and Methods}

Relevant and available sources of information suitable to generate a database of the main characteristics of artificial reefs were searched using the ISI Web of Science Database. Documents in English, French, Spanish and Portuguese were taken into consideration. Search terms were included: artificial reefs, artificial structures, monitoring and evaluation. The search was conducted by linking all the terms with the Boolean operator 'OR'. The references were screened for inclusion in the review according to a two-step process. The first focused only on the title of each study and the second on the abstract of those which had passed the first screening including the verification if each study was conducted in European coastline. In addition, non-on-line or unpublished information (e.g. reports from former studies or deployments regarding artificial reefs) was also considered.

The resulting Available data on ARs was then screened, encompassing the geographical area from Norway (northernmost point) to Spain (Strait of Gibraltar in south of Spain was considered the easternmost and southernmost point of the North-east Atlantic coastal region investigated). The information was gathered in technical reports in the scope of the European project “Artificial Reef 3D Printing for Atlantic Area” (3DPARE; [28]), by experts from each of the participating countries (Portugal, Spain, France and the United Kingdom), considering the OSPAR (2009) definition for ARs [13]. Given this, structures such as artificial islands or breakwaters, established for coastal defence purposes, were excluded from this study. Structures that were initially built with an intention other than purpose-built reefs (e.g. tyres, ship wrecks) were also excluded from the analysis as being out of the scope of the present study and due to their potential confounding effect. Based on the gathered information on AR functioning in the NE Atlantic area, the following variables were included for analysis: i) country of deployment, ii) year of deployment, iii) depth of deployment (metres), iv) building materials and shape, v) the main goal of the implementation, vi); if biodiversity monitoring was performed (target species and duration), and vii) the results of biomonitoring programs (benthos and fish species richness). It should be noted that in cases where an array of AR modules was deployed the same time (as a complex shape) in the same place, this was only considered as one AR structure. The construction material, module shape and AR function were categorized in order to evaluate the most frequently used shapes, materials and purposes. The year of deployment was also compared among countries, as were material, shape and purpose of the ARs. Six building materials and 
eleven shapes were found and categorised in Table 1 . The relationship between the different materials and designs was analysed for each country. To evaluate the function and purpose of ARs, 5 categories (adapted from [29]) were analysed: i) management and restoration, ii) protection, iii) production, iv) research purposes and, v) recreation. Finally, monitoring surveys and bio-colonization of each AR were characterized among countries, and expressed as a percentage of: a) unmonitored, b) monitored for less than 3 years, and c) monitored for at least 3 years. All the information gathered for the present work is available in the Supplementary Material.

Table 1- Artificial Reef (AR) material and shape categories present in the NE Atlantic area

\begin{tabular}{|c|c|}
\hline Material & Description \\
\hline Concrete & ARs made exclusively with concrete \\
\hline $\begin{array}{l}\text { Concrete }+ \text { other } \\
\text { material }\end{array}$ & ARs made with concrete mixed with other material such as seashells \\
\hline Natural rock & Clusters of natural rock \\
\hline Basalt & ARs made with basalt \\
\hline Waste & ARs made with reused materials such as pulverized coal ash, coal waste \\
\hline $\begin{array}{l}\text { Bags/textile filled with } \\
\text { shells or gravel }\end{array}$ & Textile bag filled with natural products, namely seashells, sand or gravel. \\
\hline Shape & Description \\
\hline Cubic shape & $\begin{array}{l}\text { Reefs with an overall cubic shape, including modules that are compact or hollow } \\
\text { with openings }\end{array}$ \\
\hline Alveolar modules & Modules of various shapes but all constituted of several cavities \\
\hline Deterring modules & $\begin{array}{l}\text { Modules for protection against sea motion or trawling in which the majority } \\
\text { consists in a compact cylinder, perfused by smaller cylinders with a prismatic base }\end{array}$ \\
\hline Cylindrical modules & Constituted only by a cylinder shape \\
\hline Pyramidal modules & Modules shaped as a pyramid \\
\hline Prismatic modules & Modules with a prismatic shape \\
\hline Reef balls & Ball shaped modules \\
\hline Rundle reef & Large vertical module with several pipes perforating horizontally \\
\hline Pipe shape & Pipe shaped module \\
\hline Irregular & ARs with no distinctive geometric shape (e.g. ARs made with natural rock) \\
\hline Multi-shape & Large modules constituted by several geometric shapes \\
\hline
\end{tabular}




\section{Results - Observed trends of ARs in the NE Atlantic area}

\subsection{NUMBERS, LOCATION AND YEAR OF DEPLOYMENT}

A total of 61 AR sites documented for the NE Atlantic area were found. These are located in Norway, Sweden, Netherlands, Germany, Denmark, UK, Belgium, France, Spain and Portugal (Fig. 1, Supplementary material - Table S1).
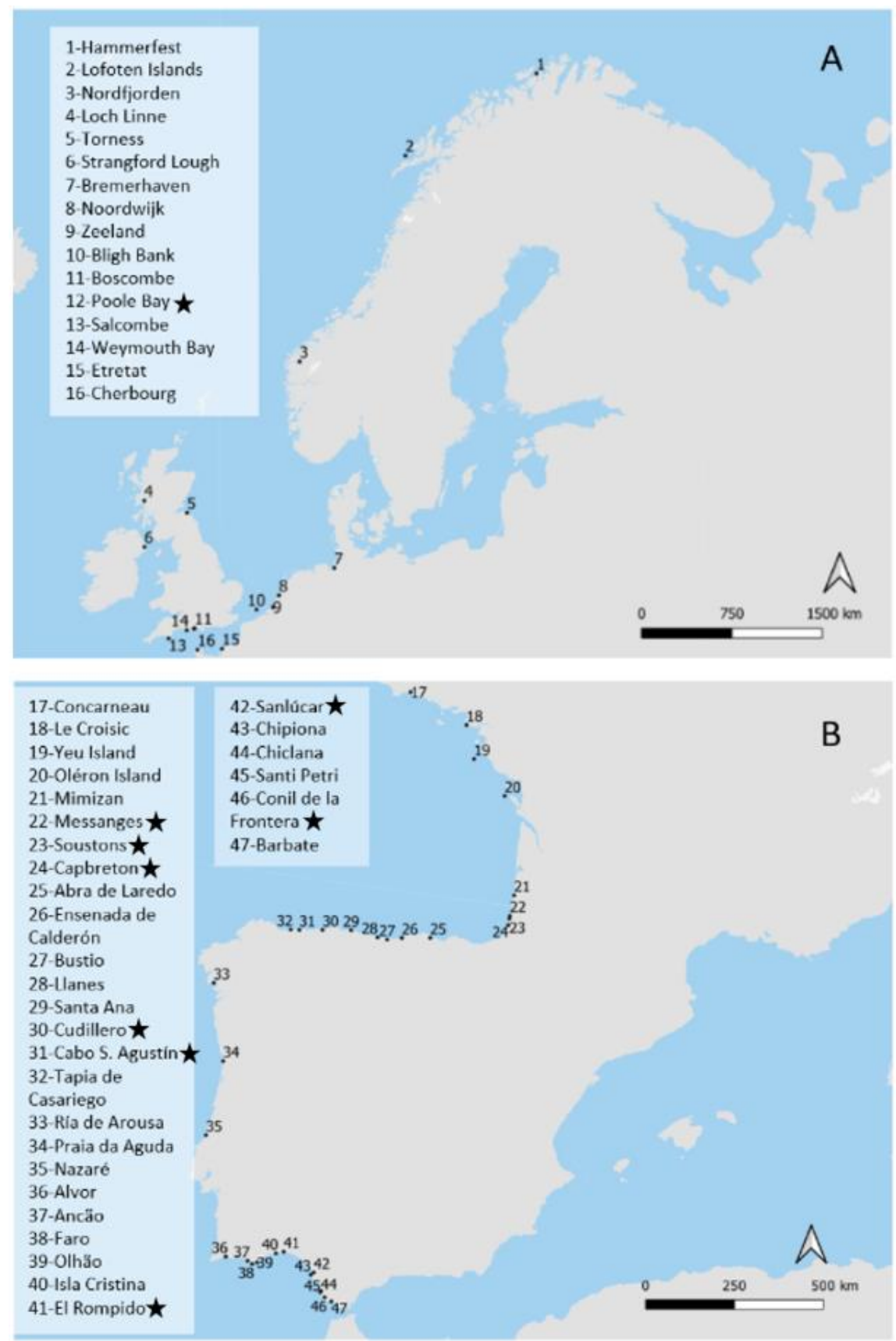

Figure 1 - Location of Artificial Reefs (ARs) across NE Atlantic area, from the NE Atlantic in Norway, Denmark, Germany, Netherlands, Belgium, UK and North Atlantic France (A) and West Atlantic France, Spain and Portugal (B). Black stars represent locations with more than one artificial reef. 
Spain has had the most AR deployments in the study area (39.3\%), while Belgium and Germany have least (1.6\% each) (Fig.2).

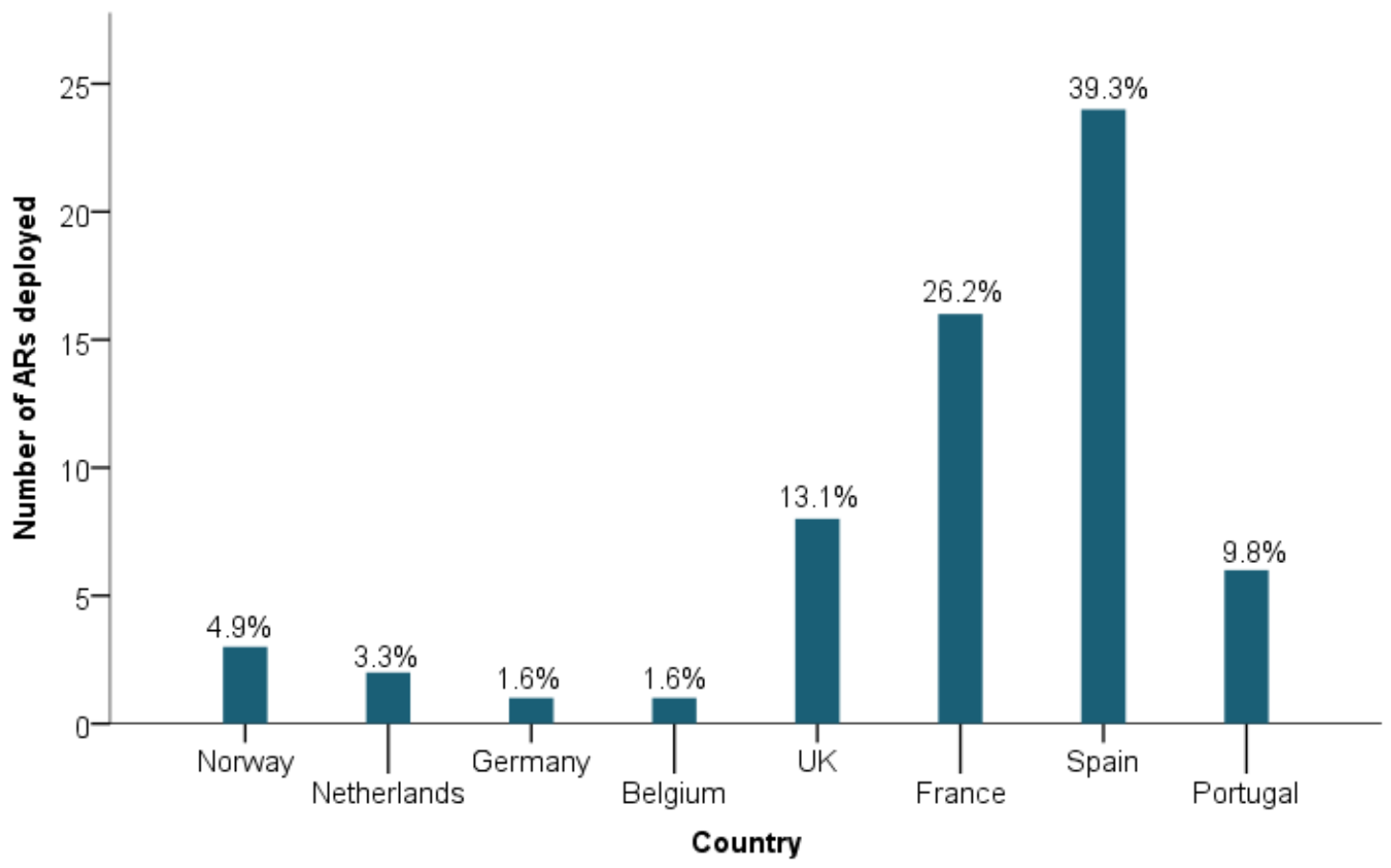

Figure 2 - Number and percentage of Artificial Reefs (ARs) deployed across the European Atlantic area $(n=61)$.

ARs have been deployed in NE Atlantic waters since 1970; the majority, 71\%, were deployed between 1990 and 2009 and 21\% between 2010 and 2018 (Fig.3). 


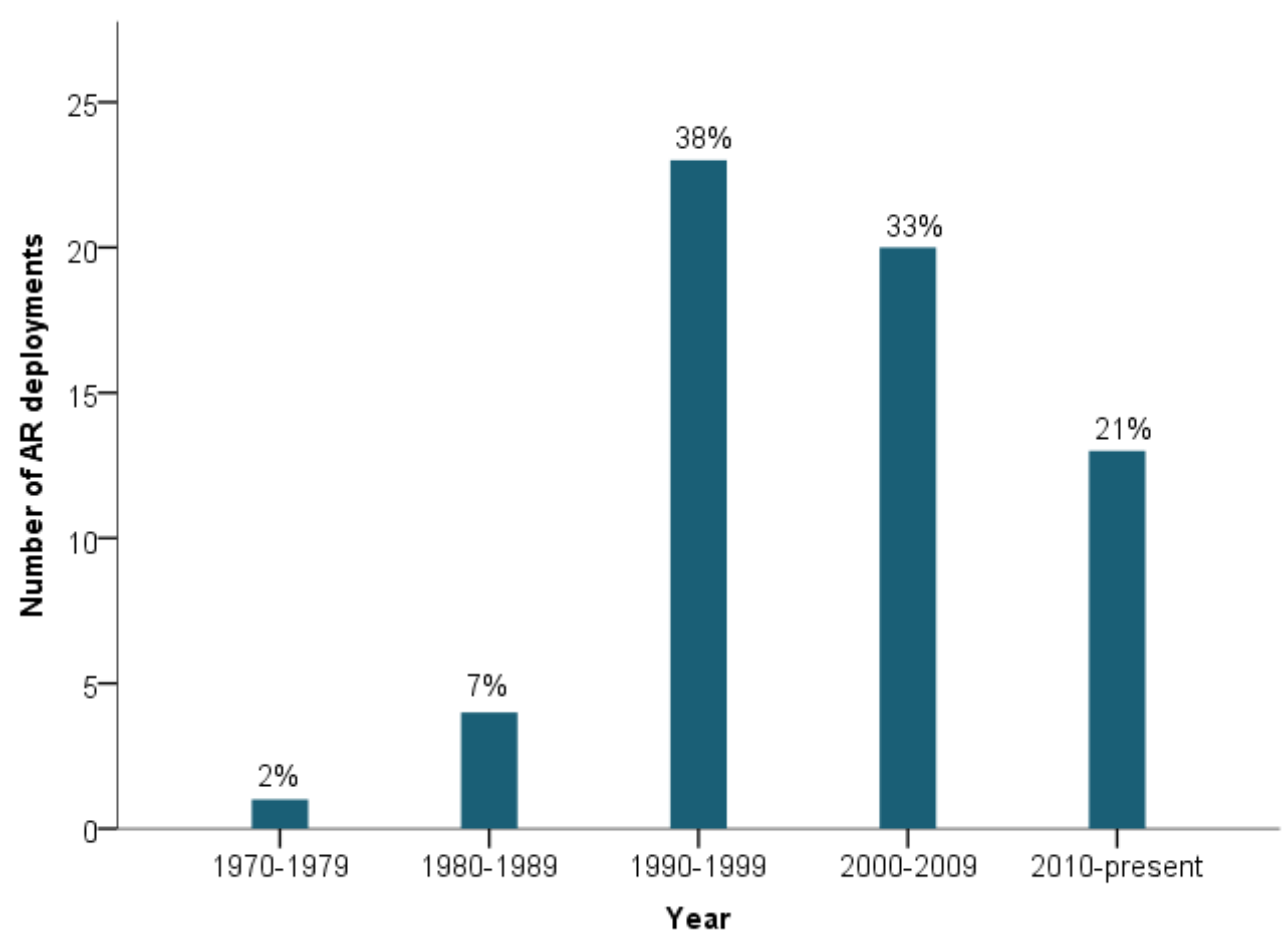

Figure 3 - Number and percentage of Artificial Reefs (ARs) deployed in different periods of time across the NE Atlantic area $(n=61)$.

Differences between the years of AR deployments within countries were more evident in Spain, with a higher number of reefs deployed during the 1990s (70.8\%), and in France, where the highest number of artificial reef deployments took place after 2000 (87.5\%). In Norway all deployments occurred after 2000.

\subsection{CONSTRUCTION MATERIALS AND DESIGN}

The majority of the reefs fabricated in the NE Atlantic area were constructed with concrete or concrete + other material since the second half of the 1980s (Figure 4; Supplementary Material - Table S1), and corresponds to $85.2 \%$ of the total ARs deployed in this area. Other materials used were natural rocks and shell materials. Shell materials started to be used more recently (2005), whereas the use of natural rock dates back to the first records of ARs in the NE Atlantic area (Fig.4). 


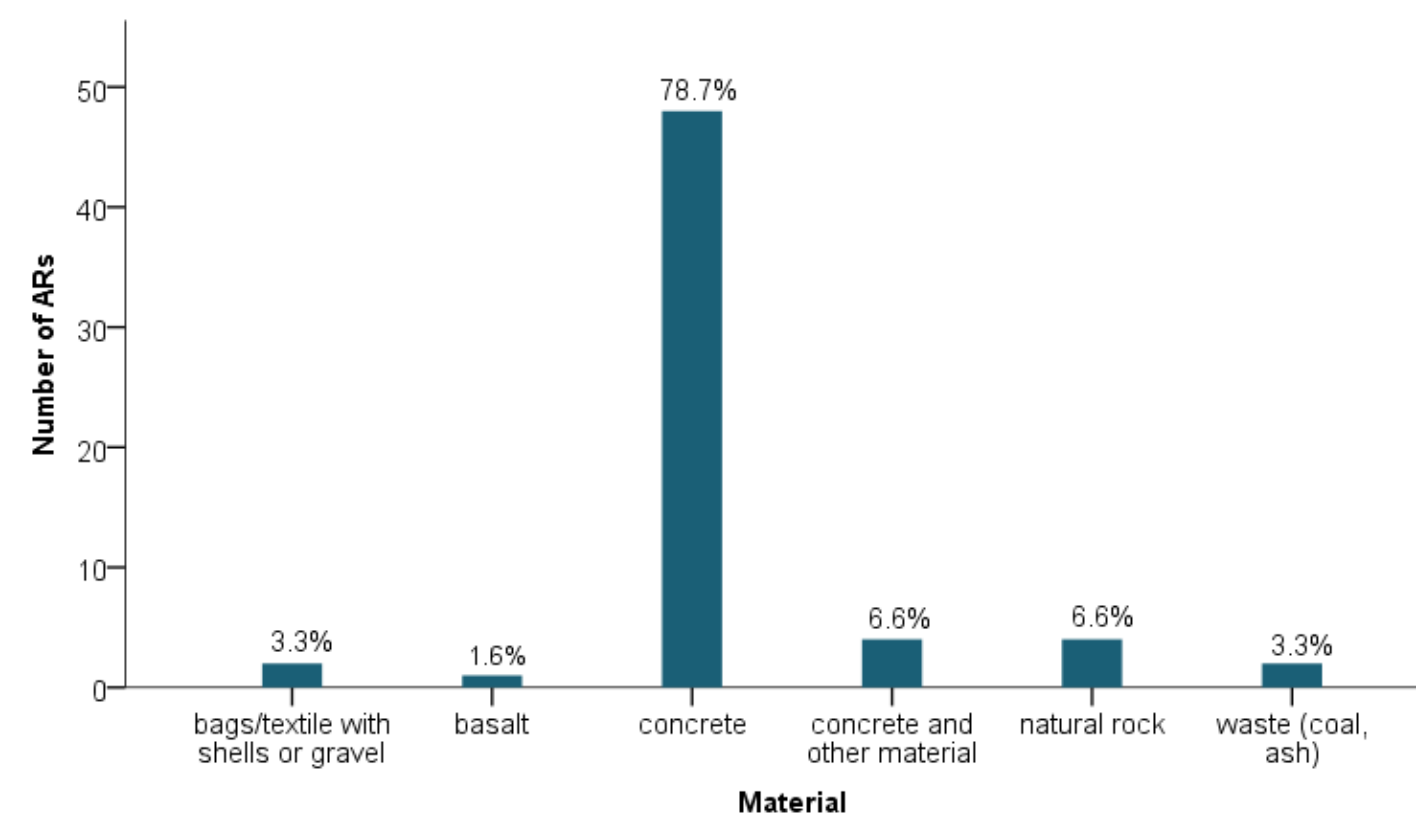

Figure 4 -Number and percentage of materials used for Artificial Reefs (ARs) construction, in NE Atlantic area $(n=61)$.

The "cubical shape" (e.g. cubic module, sabla) and "multi-shape modules" are the most deployed artificial reef shapes (16.4\% in both cases) followed by "deterring modules" (14.8\%) (Fig. 5, Table 3). However, after deployment, these shapes often end up with different and/or higher as modules have been replicated and deployed as an array. 


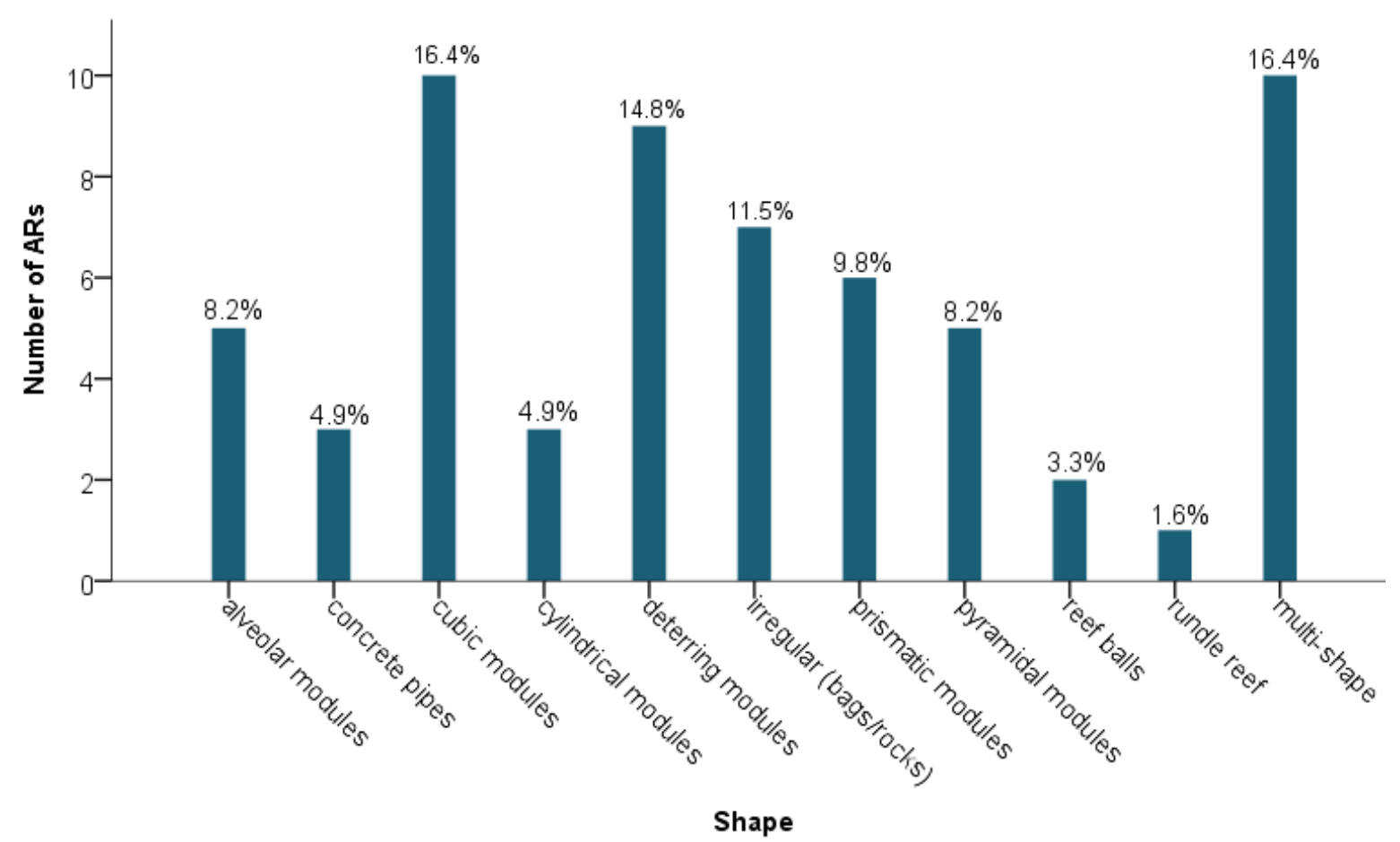

Figure 5 - Number and percentage of different shapes of Artificial Reefs (ARs, bars) deployed in NE Atlantic area $(n=61)$.

The most frequently deployed shape varies among countries. Spain have the highest number of registered deployments of deterring and alveolar modules $(n=9)$, while the UK registered the highest number of "irregular" shaped ARs $(n=4)$, which consisted of bags with shells or natural rock, whereas Portugal, Belgium and Germany only deployed ARs of a single shape (Fig.6). 


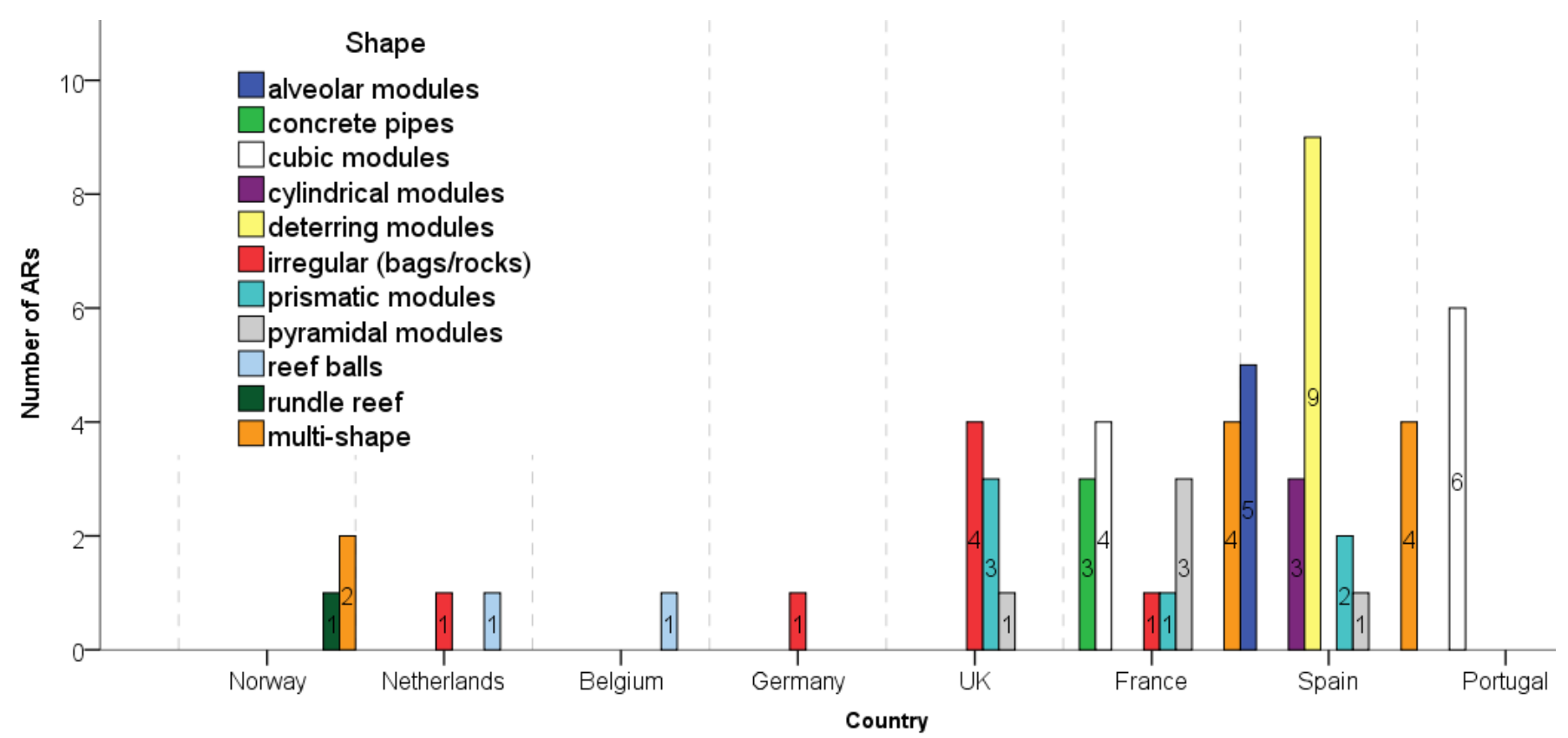

Figure 6 - Number of different Artificial Reefs (ARs) shapes deployed in each NE Atlantic country ( $n=61)$.

\subsection{AR DEPTH AND DEPLOYMENT PURPOSES}

The majority of ARs were deployed between 10 and $20 \mathrm{~m}(34 \%)$ and less than $50 \mathrm{~m}$ depth (28.3\%) (Fig. 7). Spain deployed ARs at the greatest depths and Norway the shallowest. It should be noted that there are no precise deployment depth records, or no records at all, for a considerable number of reefs (32.1\%); only a broad depth indication was found (e.g. $\mathrm{n}=15$ at $<50 \mathrm{~m}, 28.3 \% ; \mathrm{n}=2$ at $<100 \mathrm{~m}, 3.8 \%$ and $\mathrm{n}=11$, without data). 


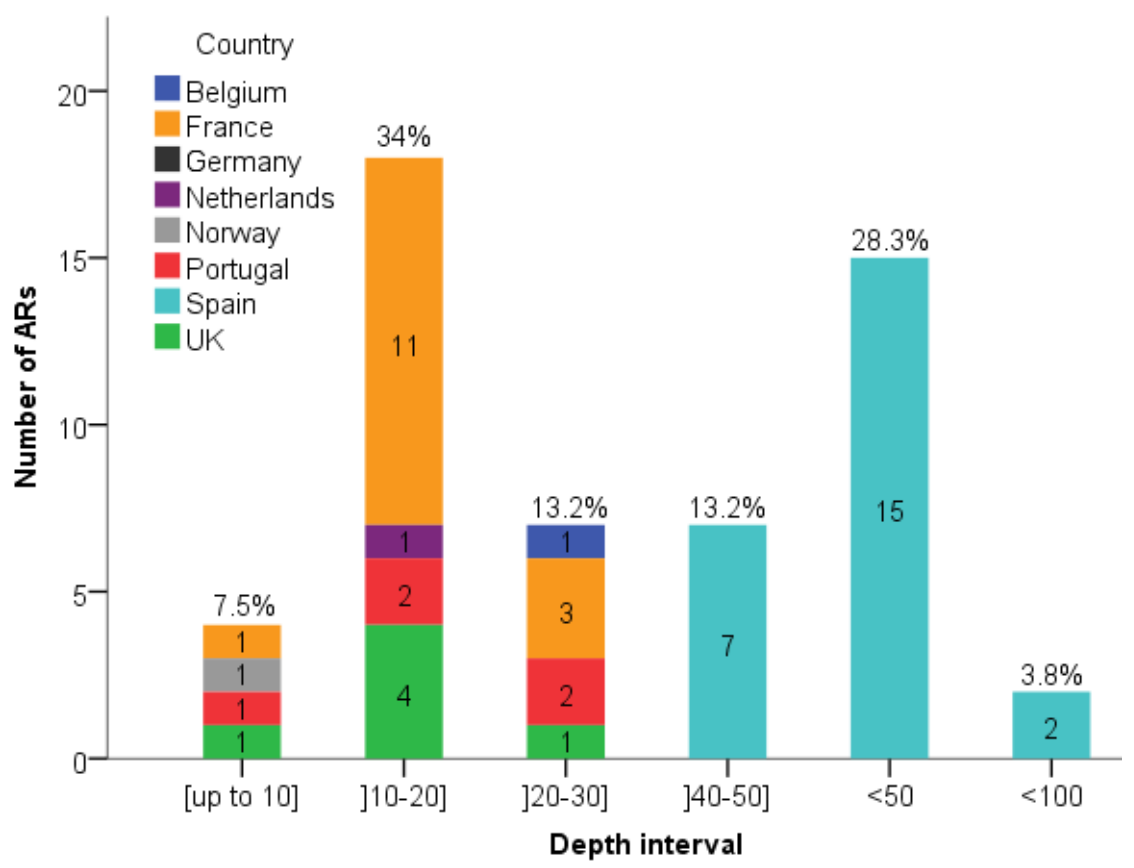

Figure 7 - Number and percentages of Artificial Reefs (ARs) deployment depths in the NE Atlantic area and in each country $(n=53)$.

The main goals of AR deployments have varied over time. Most AR deployments have aimed to enhance production (fisheries) (34.4\%), followed by protection of fish and/or habitats (31.1\%). Protection ARs were more broadly used in the 1990s and ARs aiming at recreation (scuba diving and recreational fishing) only started to be deployed since 2000 (Fig. 8).

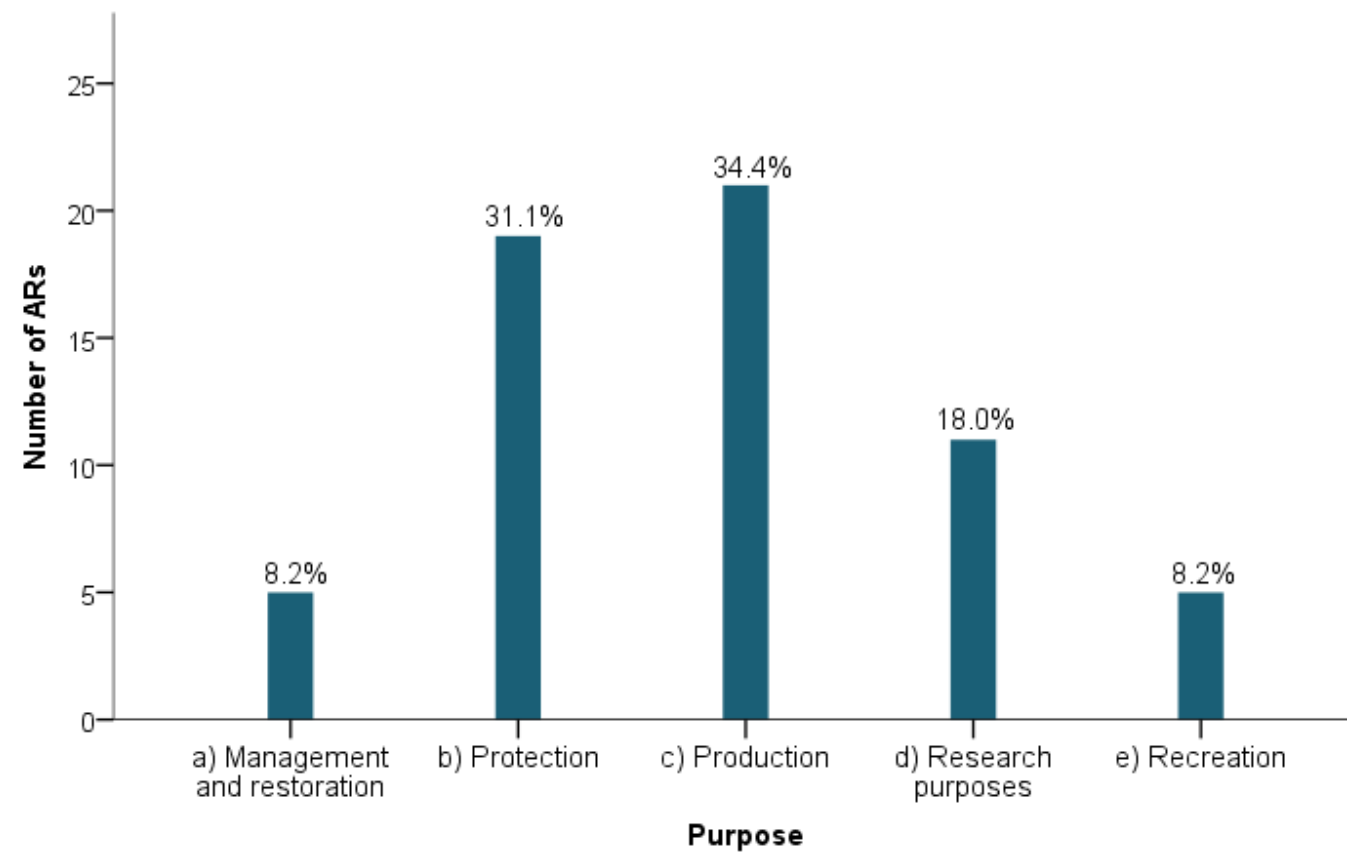

Figure 8 - Artificial Reefs (ARs) purposes (bars) across the NE Atlantic area ( $n=61)$. 
The purpose of AR deployment differs among countries (Fig. 9). Spain has the highest number of protection ARs ( $n=19)$, while France has the most deployed ARs aimed at fisheries production $(n=11)$.

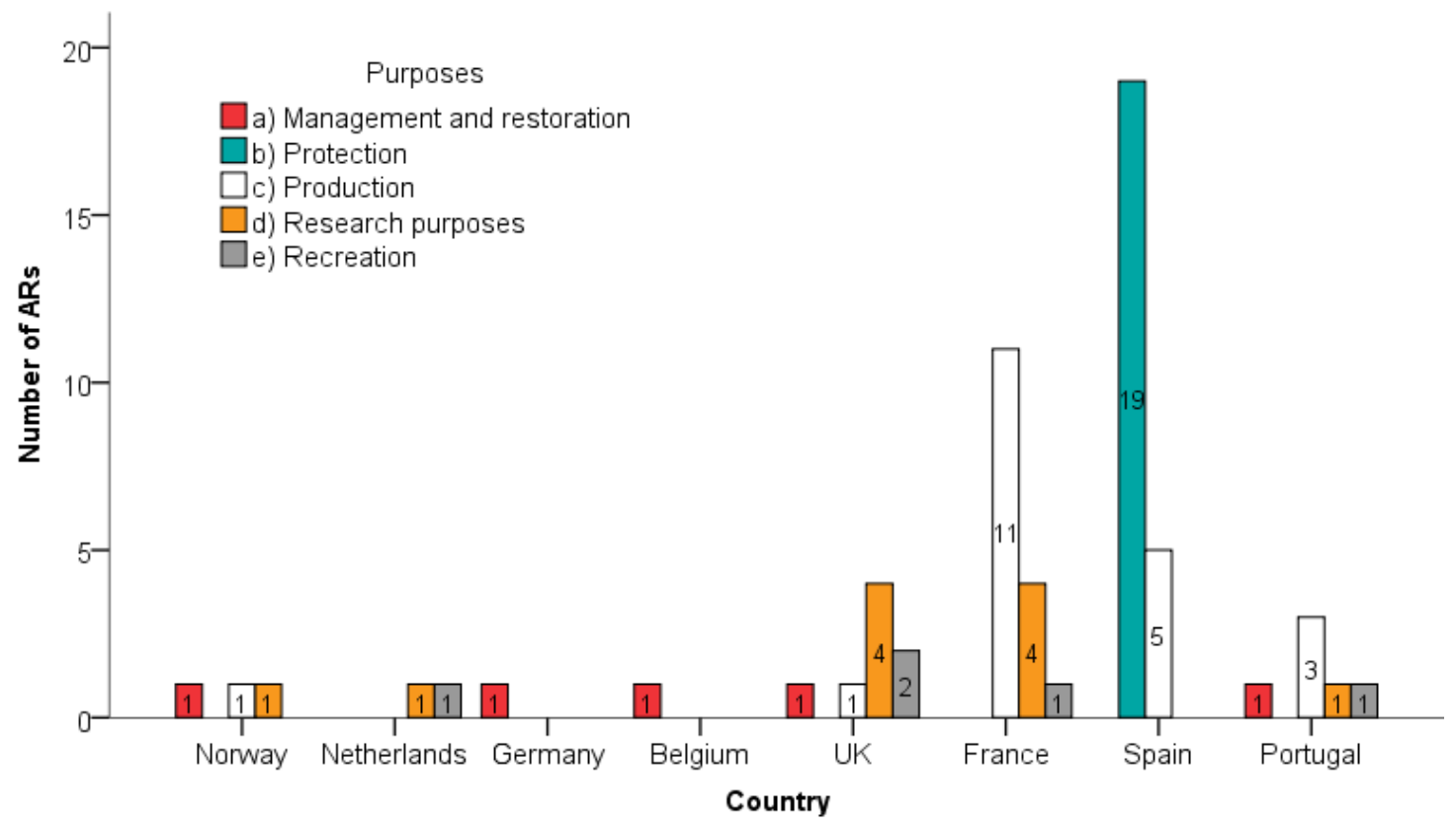

Figure 9- Purpose of Artificial Reefs (ARs) in different countries in the NE Atlantic area ( $n=61$ ) 


\subsection{BIO-COLONIZATION AND MONITORING}

Netherlands, Germany, UK, France, Spain and Portugal have all performed bio-monitoring surveys of the deployed ARs. Yet for Spain, no information could be found on AR species richness; this is a serious information gap, making comparisons difficult between the biocolonisation of reef types. In most recorded cases bio-colonization and ecological impact of ARs were assessed by measuring abundance and diversity of benthic communities and fish (Supplementary material- Table S1). From all of the ARs deployed, $67 \%$ were monitored for biodiversity assessment after deployment, however, in $26.2 \%$ of those cases, data was not available. Among available data, $31 \%$ had monitoring surveys for three years or more post deployment (Fig. 10).

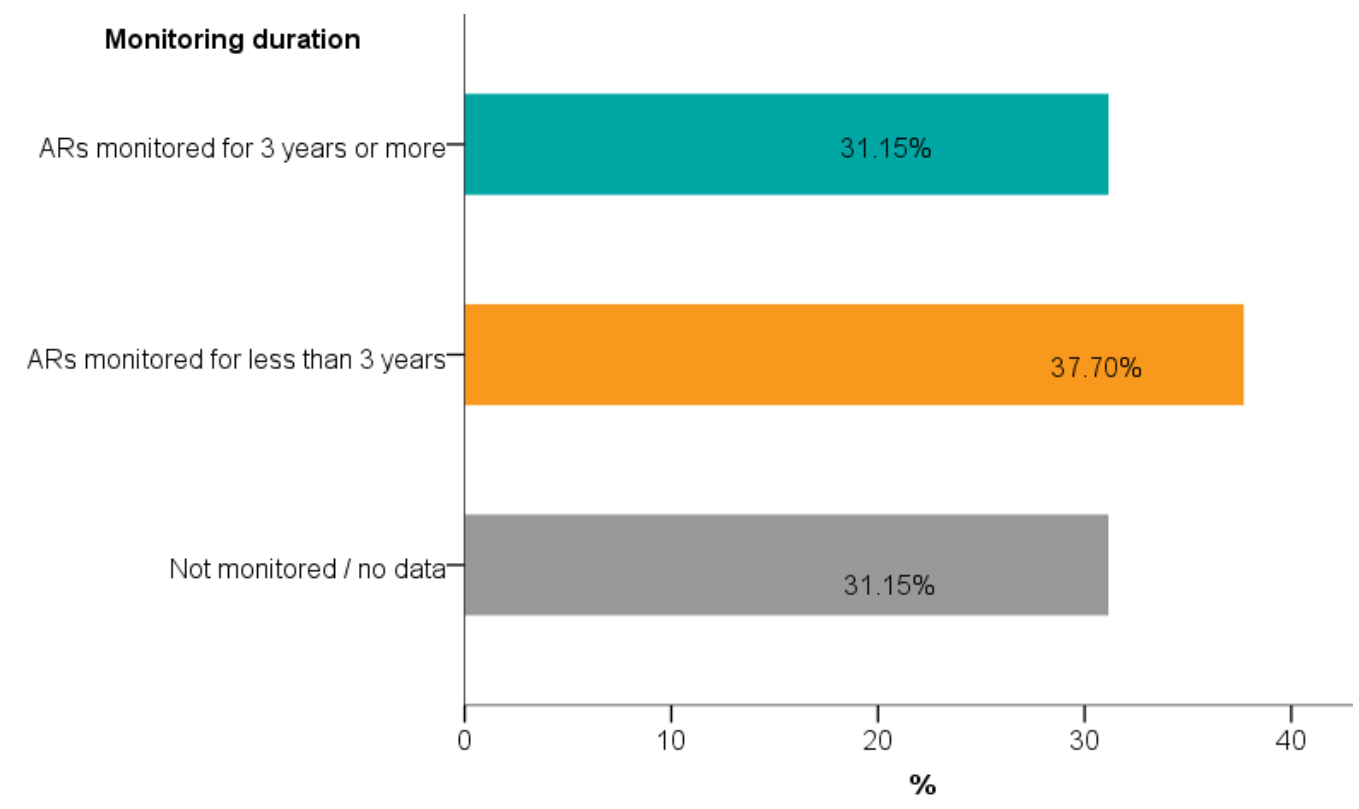

Figure 10 - Percentage of monitored and unmonitored Artificial Reefs (ARs) in the NE Atlantic area ( $n=61)$

Regarding the number of monitored ARs, the proportion of monitored to unmonitored varies between country as it is shown in Table 2 and Fig. 11. 
Table 2 - Number of monitored and unmonitored ARs in each country

\begin{tabular}{|c|c|c|}
\hline Country & Monitored & Unmonitored/No data \\
\hline Norway & 1 & 1 \\
\hline Netherlands & 1 & 1 \\
\hline Germany & 0 & 1 \\
\hline Belgium & 0 & 3 \\
\hline UK & 5 & 2 \\
\hline France & 14 & 10 \\
\hline Spain & 14 & 0 \\
\hline Portugal & 6 & \\
\hline
\end{tabular}

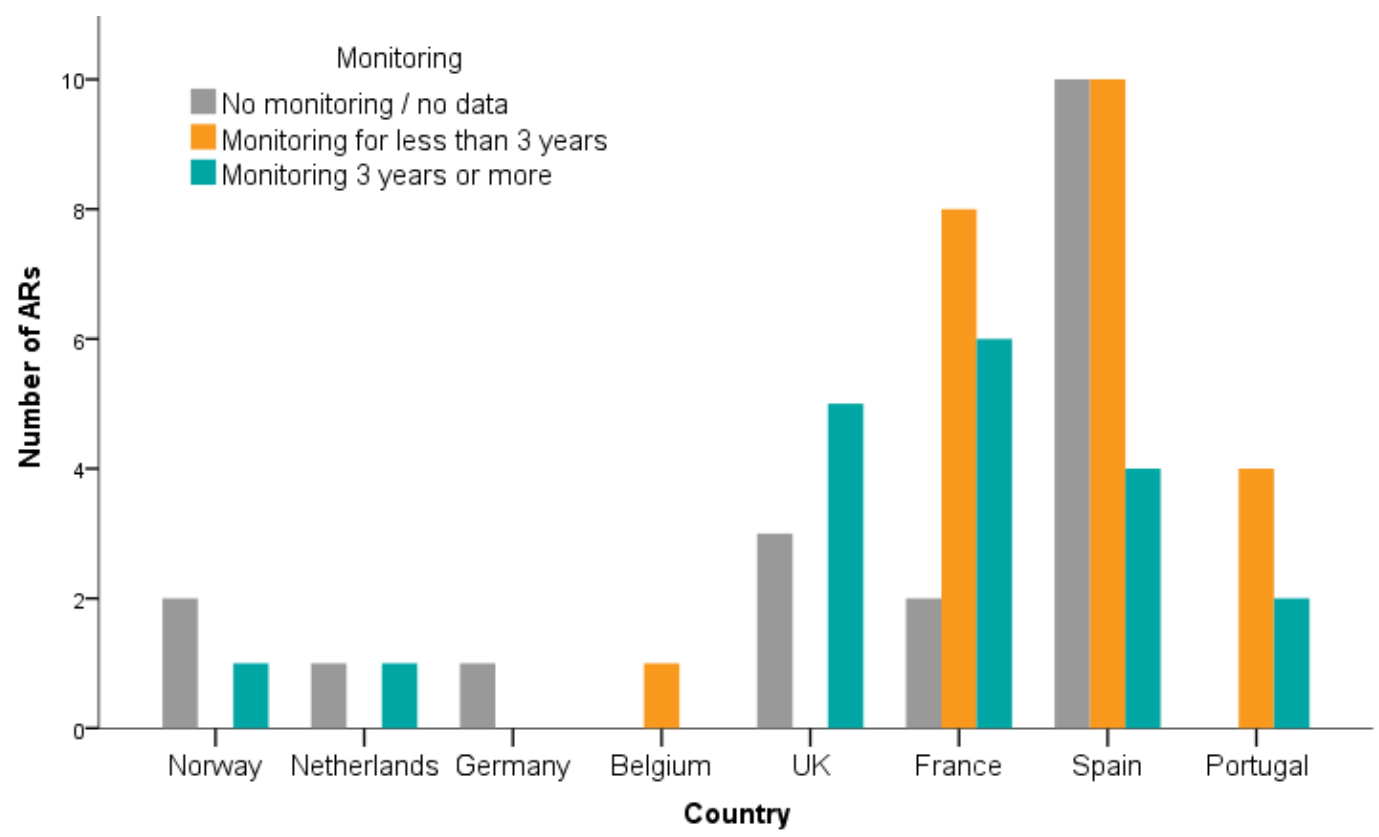

Figure 11 - Number of monitored and unmonitored Artificial Reefs (ARs) in each country of the NE Atlantic area $(n=61)$

A comparison of AR species richness in the first year of monitoring across the study area (Fig. 12; Supplementary material - Table S1) showed no significant association between the chosen material and species richness, either for fish species richness (Kruskal Wallis, $p=0.083, n=16)$, or benthic species richness $(p=0.568, n=11) f($ Fig. 12). Results of the 
comparisons between shapes showed a higher significant positive association of fish species richness with cubic modules and irregular shaped ARs (Kruskal Wallis; $p=0.045$ $\mathrm{n}=16$ ) (Fig. 13). Benthic species richness was not different among different AR shapes (Kruskal Wallis, $p=0.268 n=11$ ) (Fig. 13).

However, it should be noted that these results must be interpreted with caution due to the small sample size, different sampling years, differences in monitoring effort and biotic and abiotic environment of each country where ARs were deployed.
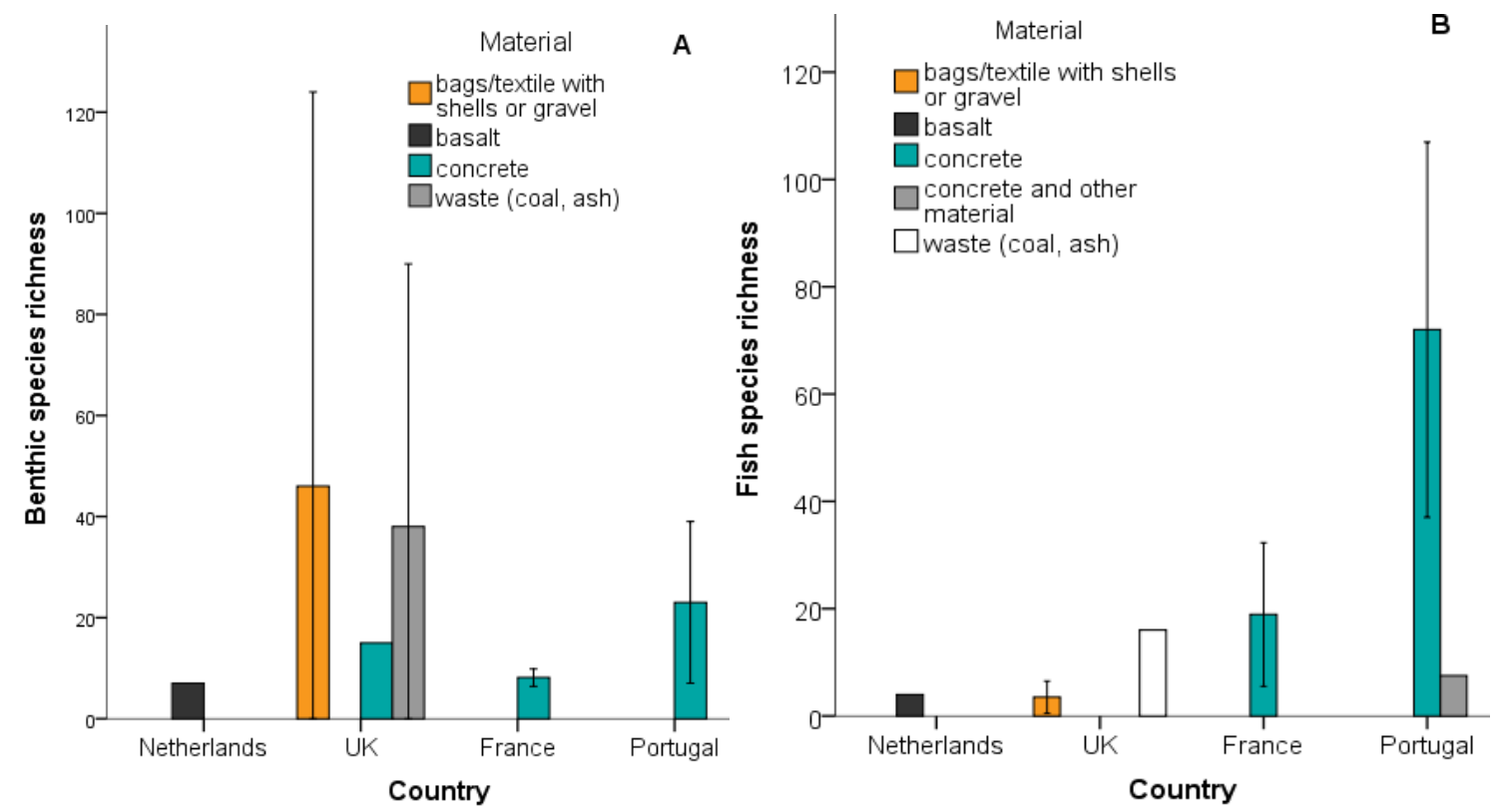

Figure 12 - Differences in species richness (Benthic - A; Fish - B) among different Artificial Reef (AR) materials found in Netherlands, UK, France and Portugal during the $1^{\text {st }}$ year of monitoring. 


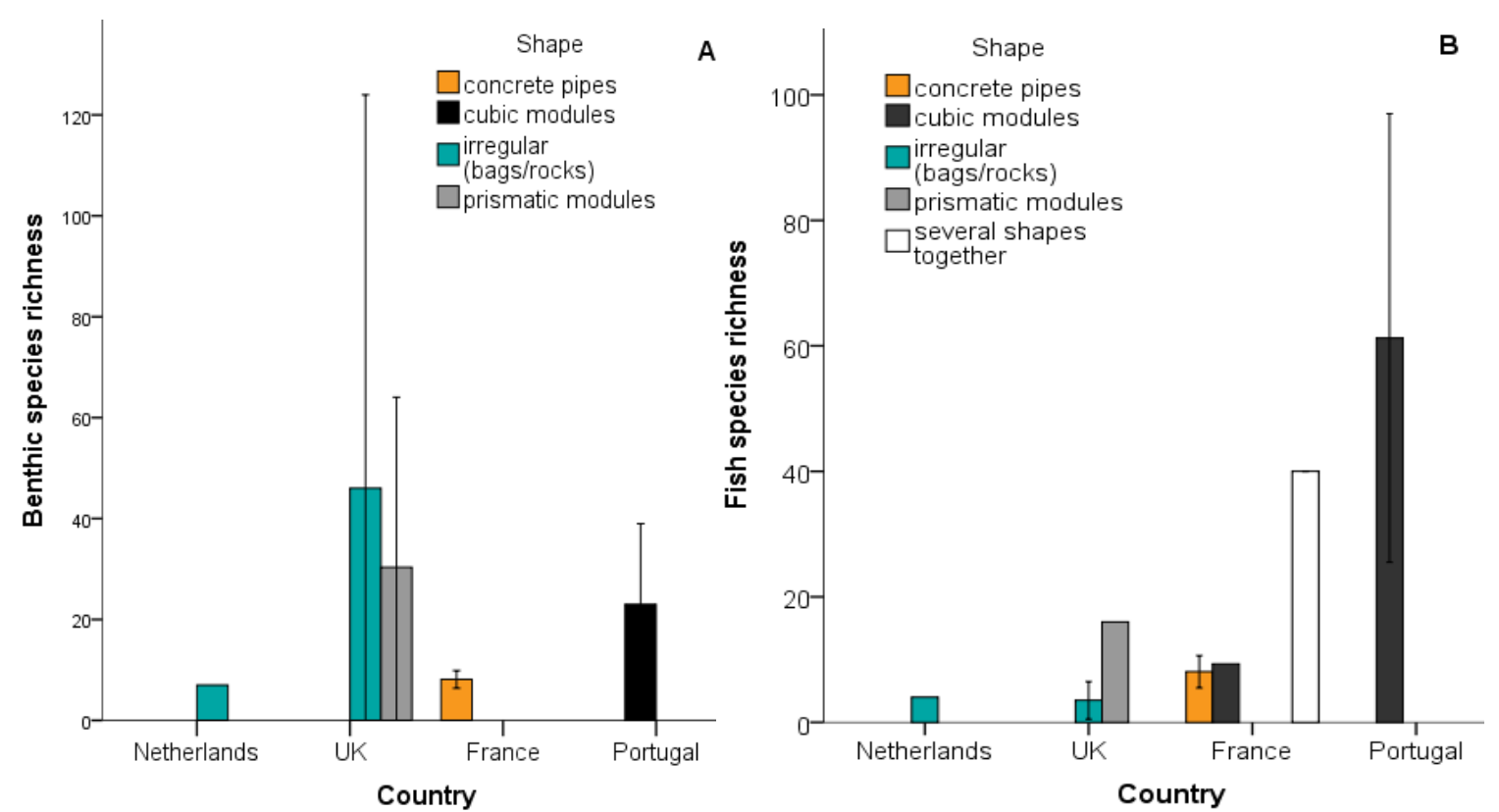

Figure 13 - Differences in species richness (Benthic - A; Fish - B) among different shapes of ARs found in Netherlands, UK, France and Portugal during the $1^{\text {st }}$ year of monitoring.

\section{Discussion - Considerations and future perspectives}

\subsection{NUMBERS, LOCATION AND YEAR OF DEPLOYMENT}

Among the sixty-one ARs along the NE Atlantic coastal area, Spain has the highest number of ARs, with most deployed in the 1990s. This is most likely due to the Multi-Annual Guidance Programme (MAGP) on ARs, which was carried out by the Spanish Government under the supervision of the European Economic Community (EEC) between 1987-1991. This programme attempted to unify criteria (e.g., materials, design, place selection, etc.) for all future ARs to be established in the Spanish coastal zone and provided funds to boost the deployment of a considerable number or ARs during the 1990s, namely on the NE Atlantic coast.

In comparison, France and Norway registered the most recent deployments (2000s). The recent deployments in France after 2000 can be explained by the increase in research programmes, as well as by the expansion in the reef construction field since the late 1990s [30]. Belgium and Germany registered the lowest number of AR deployment, possibly due to their smaller coastline. 


\subsection{DEPTH AND DEPLOYMENT PURPOSES}

The objectives of AR deployments have changed over the past 50 years. In the 1970-90s, artificial reef deployment was mostly associated with fish/habitat protection goals, followed by fisheries production. Since the 2000s there has been an increase in ARs for recreation, at the expense of protection reefs, suggesting a greater socioeconomic value associated with these leisure activities [31]. In Spain, one of the main goals of the MAGP was the protection of over-exploited coastal areas from trawl fisheries, which had a negative impact on habitats and biodiversity in the Atlantic coast [32] and it reflects the fish/habitat protection goal as being of major overall importance. In comparison, in France, most of the reefs deployed on the Atlantic coast have been directed towards fisheries production. Prior to 2000 most of ARs were designed as anti-trawling devices. However, this trend has shifted after 2000. The strategy for protecting endangered habitats became focused on better application and enforcement of laws instead of using anti-trawling ARs, which were proven to be harder to sustain by the local communities $[30,33]$. As such, thereafter, most of the deployed ARs aimed at fisheries production, explaining the higher number of this type of reef in France. In Portugal, most of ARs deployed until 2000 were for research purposes and trials to determine usefulness for fish stock management. In the 90s the first ARs were deployed in the scope of a pilot project in the Algarve to assess the performance of ARs for fish protection, selective fishing and biodiversity enhancement [34]. Following the results of these research programmes, AR deployments focused on fisheries production and biodiversity enhancement, always combined with recreational diving and research as complementary purposes [12,35]. These international differences likely reflect regional issues that were detected by the governmental authorities at particular times. In any situation, the implementation of protection and production ARs was linked to a greater potential to restore a degraded or endangered ecosystem, reinforcing the idea that ARs should not be strictly divided into 'single purpose'" categories (e.g. fisheries productivity and/or enhancement and habitat protection) [6,11,36]. Most of the artificial reef deployments aimed at being multipurpose in order to maximise the benefits of a given financial investment. Indeed, reefs designed against trawling were also expected to include elements (e.g. physical habitat) which would increase the biomass of the biota in the deployment area, either by enhancing production or attracting fauna $[14,24]$. Another factor deeply connected with AR purpose and success is the deployment 
depth. The majority of the ARs were deployed at $<50 \mathrm{~m}$ depth, mainly at $10-20 \mathrm{~m}$. The reefs deployed at greater depths $(>20 \mathrm{~m})$ were designed to act as trawling fisheries deterrents, since this fishing activity usually takes place in deeper waters [37]. This type of reef was mostly deployed in Spain, which, accordingly, registered higher deployment depths. Independently of these differences verified among countries and years, it is of crucial importance to have solidly defined and quantified goals towards the utilization of ARs $[14,25]$. Indeed, verifying if the objectives established a priori of reef deployment have been met, and that ARs are actually working. This evaluation must be undertaken and focus on research and monitoring programmes that clearly evaluate the cost-benefits of ARs in relation to the proposed goals [25]. Due to the growing interest in the use of ARs as means for ecosystem restoration and to mitigate increasing anthropogenic influences [38-40] it is essential that establishment is fully justified and guidance for management is of critical importance $[38,41]$.

\subsection{CONSTRUCTION MATERIALS AND DESIGN}

Construction materials of the ARs have also changed over the years. However, concrete is still the most used material, especially in the 1990s, followed by an increase in the use of added materials like seashells, ashes and sewage sludge in the 2000s. A trend towards the use of products like seashells has been noticed more recently. This is in accordance with the greater awareness of environmental issues and application of more sustainable policies, as well as the use of natural materials with less environmental impact, such as clay, sand, cellulose fibre, geopolymers and seashells [42]. Despite the use of innovative materials and additives, the use of cement seems to be recurrent, and is frequently used as a binder for novel materials $[42,43]$. When choosing a material for building ARs it is not only important to consider the sustainability, environmental impacts and structural integrity of the material immersed in water for long periods of time, but also to assess its bio-colonization capacity and surface orientation of the $A R$, although these factors are though only to influence in the first stages of colonization $[44,45]$. Regarding the AR design/shape the "cubic" and "multi-shape" were the most commonly deployed (each around $16.4 \%$ of the total ARs deployed), being in accordance with previous studies that reported cubical modules as the most deployed shape [3]. Typically, AR designs seek to identify shapes that are comparable to the receiving habitat and appropriate for the species 
encountered $[46,47]$. It is also known that certain features benefit certain organisms. For example, ARs with a higher vertical relief can enhance larval settlement $[46,48]$. An AR with incorporated voids is also known to serve as functional habitat for benthic species [49]. However, in the present study, materials and shape specific features (composition, rugosity, holes, voids, patterns), and chosen rationale, are rarely detailed in the literature. Only the general shape, size and a broad description of the material was reported. In most cases, ARs were built and designed by construction or private companies, which did not publish the results in a scientific format, nor were they peer reviewed. Only more recently, AR deployments and studies have been coordinated and executed by scientists, governments and non-governmental organizations, allowing the research to be more widely published and available for consultation and replication [30]. The layout of AR deployments on the seabed is also an important factor to consider, as the AR units are commonly deployed together creating an array. Observations on isolated modules can provide the basis for comparison with observations in AR arrays, however, direct attempts to associate species richness with the shape or material of an AR module per se should be avoided once individual observation can underestimate the estimated benefits. For example, at Le Croisic and Yeu Island in France, $840 \mathrm{~m}^{3}$ of ARs were deployed in three rectangular zones [50,51]. All these AR modules together create a "village", which has a much higher complexity than an individual block, providing a higher habitat connectivity and structural features which can influence species richness [30].

\subsection{BIO-COLONIZATION AND MONITORING}

From the gathered data regarding ARs in the NE Atlantic, $68 \%$ of the reefs had been monitored, but only $31 \%$ of them had been monitored for at least 3 years. Even within the monitored reefs, not all cases had published data (nor made public in any form, such as grey literature) and others (e.g. Spain) only recorded a categorical evaluation (e.g. increase or decrease in biodiversity from year to year) or used different biodiversity assessment methods. For instance, in some cases only species richness was taken into account, while in others only biomass [52,53], thereby, making comparisons and evaluation analysis difficult. It should also be noted that the available data is only relative to benthic and fish species richness and/or biomass, and surveys had not been undertaken simultaneously, revealing the need for a more comprehensive multi-species monitoring. Organisms such as 
primary producers (e.g. macroalgae) should also be taken into account and surveyed within the same artificial reef area [54] to capture the entire ecosystem generated by the artificial reef structures. However, information regarding absence of monitoring programmes and duration most probably do not correspond to reality, since a monitoring programme of at least 5-years post-deployment is mandatory and imposed in the European Union [15]. This suggests that the lack of AR monitoring data from the NE Atlantic area may be related to the fact that private companies were in charge of most of monitoring campaigns, not all following the same methods and scientific procedures in order to obtain robust scientific data. As such, the majority of the data lacks records of species diversity and abundance and is neither published nor peer-reviewed. It might have been only presented to the funding authority, and is not available to the public [30], making it more difficult to make progresses towards ARs efficiency evaluation. The lack of colonisation data may also be related to the main purpose of the AR. For example, if it is to stop fishing boats from trawling in a certain area, the colonization data may not have been considered so relevant and not included in the evaluation plan. Regarding construction materials, studies from other regions outside of NE Atlantic area suggest that concrete modules attracted a higher number of species and biomass, and in some cases even higher than in surrounding natural reefs $[46,55]$. Yet, no association between AR material and species richness was found in this review. Concerning AR shape however, a positive significant association of vertebrate/fish species richness with cubic modules and irregular shaped ARs was found. Benthic species richness was not different among different module shapes. Nonetheless, the lack of data and available information make it difficult to visualise any pattern as well as to accurately identify the best association between reef features and bio-colonization. Besides, the limited access to data from monitoring programmes, the evolution of colonization of identical ARs can also significantly vary depending on the artificial reef location, and species richness can naturally vary within the same location and along a latitudinal gradient $[56,57]$. In addition, differences in time, scale, location, and replication of the biological assessments prevent an adequate comparison. Indeed, the lack of available data regarding the colonisation organisms of ARs in the NE Atlantic area is striking and should be considered for any future artificial reef project. In this sense, the establishment and use of a standard protocol for AR monitoring is of paramount importance, since it contributes to reduce the information gaps and provide data in a "scientific friendly" format. Studies and 
assessments on ARs should follow a standardized methodology and a guidance protocol, allowing to proceed under the same guidelines in a wider geographical scale and not only under regional interests [14]. This kind of guidance tool, besides providing scientific data in a usable way, also contributes to a deeper understanding of AR deployment issues, such as how to minimize their potential negative effects, i.e. introduction and settlement of nonindigenous and invasive species; release of toxic compounds to the water column; changes in bottom currents; increase in the sediment organic content due to the increase of benthic and fish communities associated with ARs; etc [58]. In addition, a standardized protocol should also be applied a priori to AR deployments in pre-deployment monitoring campaigns, since, in order to carry out a proper assessment of AR deployment, an evaluation and characterization of the receiving habitat is of extreme importance [59]. These data would considerably help to solidify conclusions regarding the success of the implementation of ARs [60] and the settlement of realistic goals. Another crucial component for evaluation of the success of ARs is the comparison with nearby natural reefs, assuming they are located in a similar environment. This permits a comparison of levels of biodiversity and ecosystem structure and also to assess how the deployment of the ARs have influenced established communities in the natural reefs [46,61] (i.e. production vs. attraction theory [62]).

\subsection{Final remarks}

There is a growing interest in multifunctional ARs and the incorporation of AR design in new coastal infrastructures. One of the objectives of the present study was to identify optimal $A R$ characteristics to enhance biodiversity and ecosystem services along this exposed Atlantic coastline. The lack of information and available monitoring data made this difficult to achieve. Taking this into account, a major management priority is the development and implementation of a standardized protocol including a detailed design and deployment characterisation, materials used, shapes, design of array and biological monitoring and socioeconomic aspects. This requires a co-ordinated international effort, and yet would make possible a more complete evaluation of the aims and objectives of projects. A multidisciplinary approach involving material scientists, engineers and ecologists can be extremely beneficial and ensure sustainable outcomes. 


\section{Author contributions}

BR, JF and PvdL conceptualised the study. BR, EA and JF carried out data analysis. BR drafted the manuscript. All authors collected the data, which was compiled in reports within the scope of work package 4 of the 3DPARE project, and were involved in the reviewing and editing of the manuscript.

\section{Funding and Acknowledgments}

Funding was provided by Interreg Atlantic area through the project EAPA_174/2016 3DPARE-Artificial Reef 3D Printing for Atlantic area granted to the Faculty of Sciences of the University of Porto; Bournemouth University; ESITC- École Supérieure d'Ingénieurs des Travaux de la Construction de Caen; University of Cantabria and IPMA-Instituto Português do Mar e da Atmosfera. This study had also the support of FCT (Science and Technology Foundation), through the strategic project UIDB/04292/2020 granted to MARE - Marine and Environmental Sciences Centre.

Competing interests: The authors declare no competing interests 


\section{References}

1. Bortone SA, Brandini FP, Fabi G, Otake S. Artificial reefs in fisheries management. Vol. 136, Journal of Experimental Psychology: General. 2007. 23-42 p.

2. Riggio S, Badalamenti F, D’Anna G. Artificial Reefs in Sicily: An Overview. Artificial Reefs in European Seas. 2000;65-73.

3. Fabi G, Spagnolo A, Bellan-Santini D, Charbonnel E, Çiçek BA, García JJG, Jensen AC, Kallianiotis A, dos Santos MN. Overview on artificial reefs in Europe. Brazilian Journal of Oceanography. 2011;59(SPEC. ISSUE 1):155-66.

4. Bohnsack JA, Sutherland DL. Artificial reef research: a review with recommendations for future priorities. Bulletin of Marine Science. 1985;37(1):11-39.

5. Ponti M, Fava F, Perlini RA, Giovanardi O, Abbiati M. Benthic assemblages on artificial reefs in the northwestern Adriatic Sea: Does structure type and age matter? Marine Environmental Research [Internet]. 2015;104:10-9. Available from: http://dx.doi.org/10.1016/j.marenvres.2014.12.004

6. Koeck B, Pastor J, Larenie L, Astruch P, Saragoni G, Jarraya M, Lenfant P. Evaluation of impact of artificial reefs on artisanal fisheries: Need for complementary approaches. Brazilian Journal of Oceanography. 2011;59(SPEC. ISSUE 1):1-11.

7. Harmelin J. Mediterranean marine protected areas: some prominent. Environmental Conservation. 2000;27(2):104-5.

8. Claudet J, Pelletier D. Marine protected areas and artificial reefs: A review of the interactions between management and scientific studies. Aquatic Living Resources. 2004;17(2):129-38.

9. Ashworth JS, Ormond RFG. Effects of fishing pressure and trophic group on abundance and spillover across boundaries of a no-take zone. Biological Conservation. 2005;121(3):333-44.

10. Claudet J, Pelletier D, Jouvenel JY, Bachet F, Galzin R. Assessing the effects of marine protected area (MPA) on a reef fish assemblage in a northwestern Mediterranean marine reserve: Identifying community-based indicators. Biological Conservation. 2006;130(3):34969.

11. Dupont JM. Artificial reefs as restoration tools: A case study on the West Florida shelf. Coastal Management. 2008;36(5):495-507.

12. Jensen A. Artificial reefs of Europe: Perspective and future. ICES Journal of Marine Science. 2002;59(SUPPL.).

13. OSPAR COMMISSION. Assessment of construction or placement of artificial reefs . London: 2009 Biodiversity Series, publ no 438/2009 27 p. 2009;(438):2009.

14. Lima JS, Zalmon IR, Love M. Overview and trends of ecological and socioeconomic research on artificial reefs. Vol. 145, Marine Environmental Research. Elsevier Ltd; 2019. p. 81-96.

15. Seaman W. Artificial reef evaluation with application to natural marine habitats [Internet]. Vol. II, America. 2000. 246 p. Available from: http://books.google.de/books?id=JyJMuPPdsMwC

16. Hawkins SJ, Pack KE, Firth LB, Mieszkowska N, Evans AJ, Martins GM, Åberg P, Adams LC, Arenas F, Boaventura DM, Bohn K, Borges CDG, Castro JJ, Coleman RA, Crowe TP, Cruz T, Davies MS, Epstein G, Faria J, Ferreira JG, Frost NJ, Griffin JN, Hanley M, Herbert RJH, Hyder K, Johnson MP, Lima FP, Masterson-Algar P, Moore PJ, Moschella PS, Notman GM, 
Pannacciulli FG, Ribeiro PA, Santos AM, Silva ACF, Skov MW, Sugden $H$, Vale $M$, Wangkulangkul K, Wort EJG, Thompson RC, Hartnoll RG, Burrows MT, Jenkins SR. The Intertidal Zone of the North-East Atlantic Region. Interactions in the Marine Benthos. 2019. 7-46 p.

17. Hiscock, K., Christie, H., Bekkby T 2018. T. Interactions in the Marine Benthos - Global Patterns and Process. Systematics Association [Internet]. 2018 [cited 2020 Sep 8]. p. Volume 87. P47-60. Cambridge University Press. Available from: https://books.google.pt/books?hl=pt-PT\&lr=\&id=DbkDwAAQBAJ\&oi=fnd\&pg=PR9\&dq=Hiscock,+K.,+Christie, + H., + Bekkby, + T. $+2018 .+$ The+Ecolo gy+of+Rocky+Subtidal+Habitats+of+the+North+east+Atlantic.+In:+Hawkins,+S.J.,+Bohn,+K.,+Firth,+L.B.+and+Williams,+G.A.+(eds.).

18. OSPAR Commission | Protecting and conserving the North-East Atlantic and its resources [Internet]. [cited 2020 Sep 8]. Available from: https://www.ospar.org/

19. Relini, G., Zamboni, N., Tixi, F., \& Torchia G. Patterns of sessile macrobenthos community development on an artificial reef in the Gulf of Genoa (northwestern Mediterranean). Oceanographic Literature Review. 1995;7 (42):589.

20. Risso-de Faverney C, Guibbolini-Sabatier ME, Francour P. An ecotoxicological approach with transplanted mussels (Mytilus galloprovincialis) for assessing the impact of tyre reefs immersed along the NW Mediterranean Sea. Marine Environmental Research [Internet]. 2010;70(1):87-94. Available from: http://dx.doi.org/10.1016/j.marenvres.2010.03.007

21. Brickhill, M.J., Lee, S.Y., and Connolly RM. Fish and artificial reefs : attractive or productive association ? Fishes associated with artificial reefs : attributing changes to attraction or production using novel approaches. 2017;67(November):53-71.

22. Firth LB, White FJ, Schofield M, Hanley ME, Burrows MT, Thompson RC, Skov MW, Evans AJ, Moore PJ, Hawkins SJ. Facing the future: The importance of substratum features for ecological engineering of artificial habitats in the rocky intertidal. Marine and Freshwater Research. 2016;67(1):131-43.

23. Cresson P, Le Direach L, Rouanet E, Goberville E, Astruch P, Ourgaud M, Harmelin-Vivien M. Functional traits unravel temporal changes in fish biomass production on artificial reefs. Marine Environmental Research [Internet]. 2019;145(November 2018):137-46. Available from: https://doi.org/10.1016/j.marenvres.2019.02.018

24. Lokesha, Sundar V, Sannasiraj SA. Artificial Reefs: A Review. The International Journal of Ocean and Climate Systems. 2013;4(2):117-24.

25. Becker A, Taylor MD, Folpp H, Lowry MB. Managing the development of artificial reef systems: The need for quantitative goals. Fish and Fisheries. 2018;19(4):740-52.

26. Champion C, Suthers IM, Smith JA. Zooplanktivory is a key process for fish production on a coastal artificial reef. Marine Ecology Progress Series. 2015 Dec 15;541:1-14.

27. Lee MO, Otake S, Kim JK. Transition of arti fi cial reefs ( ARs ) research and its prospects. 2018;154(January):55-65.

28. 3DPARE [Internet]. [cited 2020 Nov 4]. Available from: https://www.giteco.unican.es/proyectos/3dpare/index.html

29. Fabi G, Scarcella G, Spagnolo A, Bortone SA, Charbonnel E, Goutayer JJ, Haddad N, Lok A, Trommelen M. Practical guidelines for the use of artificial reefs in the Mediterranean and the Black Sea [Internet]. GFCM. Studies and Reviews. 2015. 84 p. Available from: 
http://www.fao.org/documents/card/en/c/f55a6cea-b550-435a-ac9d-601ae7870a25/

30. Tessier A, Francour P, Charbonnel E, Dalias N, Bodilis P, Seaman W, Lenfant P. Assessment of French artificial reefs: due to limitations of research, trends may be misleading. Hydrobiologia. 2015;753(1).

31. Tynyakov J, Rousseau M, Chen M, Figus O, Belhassen $\mathrm{Y}$, Shashar N. Artificial reefs as a means of spreading diving pressure in a coral reef environment. Ocean and Coastal Management [Internet]. 2017;149:159-64. Available from: https://doi.org/10.1016/j.ocecoaman.2017.10.008

32. Gomez-Buckley MC, Haroun RJ. Artificial reefs in the Spanish coastal zone. Bulletin of Marine Science. 1994;55(2-3):1021-8.

33. Direction inter-régionale de la mer. Document stratégique pour I' implantation des récifs artificiels. 2012;1-102.

34. Neves Santos M, Costa Monteiro C. Comparison of the catch and fishing yield from an artificial reef system and neighbouring areas off Faro (Algarve, south Portugal). Fisheries Research. 1998;39(1):55-65.

35. Monteiro CC, Santos MN. 15. Portuguese Artificial Reefs. 2000;249-61.

36. Pickering $\mathrm{H}$, Whitmarsh $\mathrm{D}$, Jensen A. Artificial reefs as a tool to aid rehabilitation of coastal ecosystems: Investigating the potential. Marine Pollution Bulletin. 1999;37(8-12):505-14.

37. Munoz-Perez JJ, Gutierrez Mas JM, Naranjo JM, Torres E, Fages L. Position and monitoring of anti-trawling reefs in the Cape of Trafalgar (Gulf of Cadiz, SW Spain). Bulletin of Marine Science. 2000;67(2):761-72.

38. Ng CSL, Toh TC, Chou LM. Artificial reefs as a reef restoration strategy in sediment-affected environments: Insights from long-term monitoring. Aquatic Conservation: Marine and Freshwater Ecosystems. 2017;27(5):976-85.

39. Seaman W. Artificial habitats and the restoration of degraded marine ecosystems and fisheries. Hydrobiologia. 2007;580(1):143-55.

40. Harris Lee. Artificial reefs for ecosystem restoration and coastal erosion protection with aquaculture and recreational amenities. Reef Journal [Internet]. 2009;1(1):1-12. Available from: http://www.artificialreef.com/reefball.org/album/==) Non-Geographic defined Photos/artificialreefscientificpapers/2006JulyLEHRBpaper.pdf

41. Jayanthi M, Patterson Edward JK, Malleshappa H, Gladwin Gnana Asir N, Mathews G, Diraviya Raj K, Bilgi DS, Ashok Kumar TK, Sannasiraj SA. Perforated trapezoidal artificial reefs can augment the benefits of restoration of an island and its marine ecosystem. Restoration Ecology. 2020;28(1):233-43.

42. Dunn K, Haeusler MH, Zavoleas Y, Bishop M. Recycled Sustainable 3D Printing Materials for Marine Environments. Conference: eCAADe 37/Sigradi 23: Architecture in the Age of the 4th Industrial Revolution, Porto, Portugal [Internet]. 2016;2(Gardiner 2011):583-92. Available from: http://papers.cumincad.org/data/works/att/ecaadesigradi2019_641.pdf

43. Mat Jusoh S, Ghazali CMR, Mat Amin KA, Mohd Zin Z, Wan Nik WMN, Mohamad N, Jarkoni NK. Innovative Uses of Recycle Waste Materials as an Artificial Concrete Reef for Estuarine Ecosystem. IOP Conference Series: Materials Science and Engineering. 2018;374(1).

44. Ushiama S, Smith JA, Suthers IM, Lowry M, Johnston EL. The effects of substratum material and surface orientation on the developing epibenthic community on a designed artificial 
reef. Biofouling [Internet]. 2016;32(9):1049-60. Available from: http://dx.doi.org/10.1080/08927014.2016.1224860

45. Schroeter SC, Reed DC, Raimondi PT. Effects of reef physical structure on development of benthic reef community: A large-scale artificial reef experiment. Marine Ecology Progress Series. 2015;540:43-55.

46. Granneman JE, Steele MA. Effects of reef attributes on fish assemblage similarity between artificial and natural reefs. ICES Journal of Marine Science. 2015;72(8):2385-97.

47. Barnabé G, Charbonnel E, Marinaro J-Y, Ody D, Francour P. Artificial Reefs in France: Analysis, Assessments and Prospects. In: Artificial Reefs in European Seas [Internet]. Springer Netherlands; 2000 [cited 2020 Jun 30]. p. 167-84. Available from: https://link.springer.com/chapter/10.1007/978-94-011-4215-1_10

48. Rilov G, Benayahu Y. Fish assemblage on natural versus vertical artificial reefs: The rehabilitation perspective. Marine Biology. 2000;136(5):931-42.

49. Rouse S, Porter JS, Wilding TA. Artificial reef design affects benthic secondary productivity and provision of functional habitat. Ecology and Evolution. 2020;(April 2019):2122-30.

50. Véron G, Denis J, Thouard E, Thébaud O GA. Les récifs artificiels. État des connaisssances et recommandations. IFREMER. 2008;25.

51. Thorin S, Boutin S, Pary B, Pioch S, Fourneau G. Étude de faisabilité pour la creation de récifs artificiels dédiés à la pêche artisanale - Rapport Phase 2. Comité départemental des pêches maritimes et des élevages marins de la Gironde,. 2013;194.

52. Moura A, Da Fonseca LC, Cúdia J, Carvalho S, Boaventura D, Cerqueira M, Leitõ F, Santos $\mathrm{MN}$, Monteiro CC. Is surface orientation a determinant for colonisation patterns of vagile and sessile macrobenthos on artificial reefs? Biofouling. 2008;24(5):381-91.

53. Cancela da Fonseca L, Boaventura D, Ré P, Pereira P, Neves dos Santos M. Caracterizaçao das Cornunidades de Macroinvertebrados Bentonicos no Sistema Recifal do Alvor (Costa Sul do Algarve). 13 Congresso do Algarve. 2007;(November 2014).

54. Tsiamis K, Salomidi M, Gerakaris V, Mogg AOM, Porter ES, Sayer MDJ, Küpper FC. Macroalgal vegetation on a north European artificial reef (Loch Linnhe, Scotland): biodiversity, community types and role of abiotic factors. Journal of Applied Phycology. 2020;1353-63.

55. Brock, R. E., \& Norris JE (1989). An analysis of the efficacy of four artificial reef designs in tropical waters. Journal of the Japan Society of Air Pollution. 1989;44(2):934-41.

56. Macpherson E, Duarte CM. Atlantic fishes. Ecography. 1994;3:242-8.

57. Floeter SR, Ferreira CEL, Dominici-Arosemena A, Zalmon IR. Latitudinal gradients in Atlantic reef fish communities: trophic structure and spatial use patterns. Journal of Fish Biology. 2004;64:1680-99.

58. Sheehy DJ, Vik SF. The role of constructed reefs in non-indigenous species introductions and range expansions. Ecological Engineering. 2010;36(1):1-11.

59. Wilding TA, Sayer MDJ. Evaluating artificial reef performance: Approaches to pre- and postdeployment research. ICES Journal of Marine Science. 2002;59(SUPPL.):222-30.

60. Becker A, Taylor MD, Folpp H, Lowry MB. Managing the development of artificial reef systems: The need for quantitative goals. Fish and Fisheries. 2018;

61. Folpp HR, Schilling HT, Clark GF, Lowry MB, Maslen B, Gregson M, Suthers IM. Artificial reefs 
increase fish abundance in habitat-limited estuaries. Journal of Applied Ecology. 2020;57(9):1752-61.

62. Smith JA, Lowry MB, Champion C, Suthers IM. A designed artificial reef is among the most productive marine fish habitats: new metrics to address 'production versus attraction.' Marine Biology. 2016;163(9):1-8. 